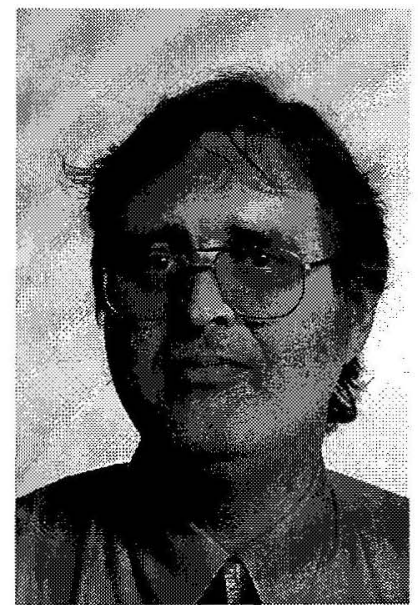

\title{
INFERRED ADAPTATIONS BY \\ DIFFERENT DEMOGRAPHIC \\ GROUPS IN NEW ZEALAND \\ REGIONAL COMMUNITIES \\ AND SETTLEMENT TYPES \\ TO LABOUR MARKET \\ CHANGES OVER THE 1986-96 \\ PERIOD
}

\author{
James Newell \\ Monitoring and Evaluation Research \\ Associates Limited (MERA)
}

\begin{abstract}
Between 1986 and 1996 rural New Zealand experienced some of the most depressed labour market conditions of the postwar period followed by a partial recovery in employment levels. This paper explores the differences in adaptation strategies for different life cycle stages and settlement types. Labour market and population accounting models are used to estimate intercensal net migration and labour market transitions respectively for different birth year cohorts for 1986-91 and 1991-96 period. The results for the two periods are compared to arrive at a first estimate of the respective role of labour market transitions and changes in net migration for each spatial unit and demographic group. Amongst other results, youth are estimated to migrate much less as an adaptation response than other age groups. Rural male and female labour market experiences over this period were strikingly different. Changes in net migration made up a much larger proportion of the adaptation for mural than minor urban or secondary urban areas.
\end{abstract}

